\title{
Brachycephalic, dolichocephalic and mesocephalic: Is it appropriate to describe the face using skull patterns?
}

\author{
Fernanda Catharino Menezes Francoㄴ, Telma Martins de Araujo², Carlos Jorge Vogel³, Cátia Cardoso Abdo Quintão ${ }^{4}$
}

The use of a standardized terminology in the medical sciences is essential for both clinical practice and scientific research. In addition to facilitating communication between professionals, it enhances the reliability of comparisons made between studies from different areas, thereby contributing to a higher level of scientific evidence. Examples of attempts made to standardize the terminology in other areas dedicated to the study of craniofacial morphology can be found in the literature. On the other hand, one can find in the orthodontic literature a variety of terms that render the consensus and communication between orthodontists and other researchers even more problematic. As an example, one could cite the use of the terms brachyfacial, mesofacial and dolichofacial, which form part of a cranial index terminology used to describe facial types. Thus, a reflection on the origin and differences of the terms used to describe the human facial phenotype may pave the way toward a consensus regarding the meaning that best represents the craniofacial patterns.

Keywords: Face. Terminology. Classification.

A padronização da nomenclatura utilizada nas ciências médicas é fundamental tanto para a prática clínica quanto para a pesquisa científica. Além de facilitar a comunicação entre os profissionais, aumenta a confiabilidade da comparação entre trabalhos de diferentes áreas, favorecendo um melhor nível de evidência científica. Exemplos de esforços, em áreas também voltadas ao estudo da morfologia craniofacial, no sentido de uniformização da terminologia podem ser encontrados na literatura médica. Por outro lado, observa-se na literatura ortodôntica uma diversidade de termos que torna mais difícil o consenso e a comunicação entre ortodontistas e demais pesquisadores. Como exemplo, pode-se citar o uso dos termos braquifacial, mesofacial e dolicofacial, terminologia relativa ao índice craniano utilizada para descrever o tipo facial. Sendo assim, a reflexão sobre a origem e diferenças dos termos utilizados para descrever o fenótipo facial humano pode ser útil ao consenso do significado que melhor representa o padrão craniofacial.

Palavras-chave: Face. Terminologia. Classificação.

${ }^{1}$ Professor of Orthodontics, Bahiana School of Medicine and Public Health (EBMSP). Professor, Specialization Program in Orthodontics, Federal University of Bahia (UFBA). Diplomate, Brazilian Board of Orthodontics and Dentofacial Orthopedics (BBO). MSc in Orthodontics, Federal University of Rio de Janeiro (UFRJ). Doctoral student in Orthodontics, Rio de Janeiro State University (UERJ).

${ }^{2}$ Professor of Orthodontics at UFBA. Coordinator of the Prof. José Édimo Soares Martins Orthodontics Center, UFBA. Former chairwoman of the Brazilian Board of Orthodontics and Dentofacial Orthopedics.

${ }^{3}$ Former chairman of the Brazilian Board of Orthodontics and Dentofacial Orthopedics.

${ }^{4} \mathrm{PhD}$ and MSc in Orthodontics, UFRJ. Associate Professor of Orthodontics, UERJ.
How to cite this article: Franco FCM, Araujo TM, Vogel CJ, Quintão CCA. Brachycephalic, dolichocephalic and mesocephalic: Is it appropriate to describe the face using skull patterns? Dental Press J Orthod. 2013 May-June;18(3):159-63.

Submitted: July 29, 2011 - Revised and accepted: December 20, 2011

" The specimens shown in the present article belong to the collection of skulls with normal occlusion of the Prof. José Édimo Soares Martins Orthodontics Center (UFBA), having been donated by Prof. Carlos Jorge Vogel.

» The authors report no commercial, proprietary or financial interest in the products or companies described in this article.

Contact address: Fernanda Catharino Menezes Franco Av. Araújo Pinho, 62/7º andar - Faculdade de Odontologia da UFBA - Brazil CEP: 40.110-150 - Canela, Salvador/BA - E-mail: fernandacatharino@gmail.com 


\section{INTRODUCTION}

Facial type assessment is in many aspects crucial for the planning and prognosis of orthodontic treatment. Facial morphology is related to factors such as volume and shape of pharyngeal airspace, ${ }^{1}$ anatomy of masticatory muscles, ${ }^{2,3}$ dentoalveolar anatomy ${ }^{4}$ and occlusion type. ${ }^{5,6}$ Moreover, the facial pattern indicates the direction of growth of the craniofacial complex ${ }^{7,8}$ and must be taken into consideration when selecting the orthodontic biomechanics. ${ }^{9}$

The terminology used to describe the craniofacial complex stemmed from classical anthropometry, which employs measurements taken in living individuals and human skulls as well as indices that represent facial proportions. ${ }^{10,12}$ The most common among these is the cranial index (which classifies skull types as brachycephalic, mesocephalic and dolichocephalic), and the facial index (which classifies the face as euryprosopic, mesoprosopic and leptoprosopic). ${ }^{11,13}$ Despite the need to standardize the terminology, in orthodontics one still notes a wide range of terms to describe the various facial types. ${ }^{14}$ The standardization of these terms in different fields of knowledge is essential to facilitate communication between researchers and allow reliable comparisons between different studies. ${ }^{15}$ In view of these issues, this article aimed to clarify the concept, origin and differences between the terms that describe the human facial phenotype.

\section{CEPHALIC AND FACIAL INDICES}

The first classification based on cranial morphology is attributed to the professor of anatomy Anders Retzius (1840). Retzius described as gentes dolichocephalae those individuals who had an elongated skull shape, and gentes brachycephalae those whose skulls were short. However, he assigned no numerical values to set the boundaries between individual types in both groups and neither did he use the intermediate term mesocephalae, which was introduced at a later time. ${ }^{14}$ The measures used by Retzius - when applied to living individuals - are known as cephalic index, and when referring to dry skulls, cranial index. ${ }^{12,13}$ These indices are calculated by determining the ratio between maximum width and maximum length of the head (Fig 1). ${ }^{12,13}$ The concept was subsequently enhanced with the definition of intermediate values, ${ }^{14}$ which provide a classification system and reflect more accurately the diversity found in human facial morphology (Table 1). ${ }^{16}$ Both the cephalic
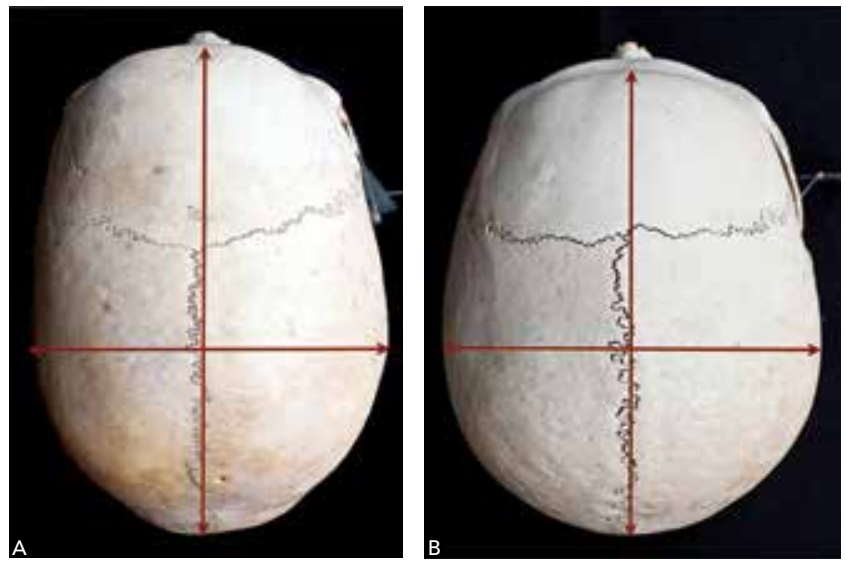

Figure 1 - Cranial index: Calculated using the ratio between the maximum width and length of the head. In A, dolichocephalic skull and in B, brachycephalic skull.

and cranial indices are therefore measures related to the shape of the skull. The index used in anthropometry to describe the face proportions is the facial index, a product of morphological facial height, measured from the Nasion (N) to Gnathion (Gn) anatomical landmarks, divided by the bizygomatic width, measured from the right to the left Zygion (Zyr-Zyl) (Fig 2). ${ }^{11,13}$ Semantically, the terms used in the facial index are derived from Greek, where the word for face is prosopon. ${ }^{14}$ According to this classification system, numerical values are assigned which establish the euryprosopic, mesoprosopic and leptoprosopic categories (Table 2). ${ }^{11,13}$

\begin{tabular}{cl} 
Table 1 - Head classification according to the cephalic index. \\
\hline Ultradolichocephalic & x-64.9 \\
Hyperdolichocephalic & $65.0-69.9$ \\
Dolichocephalic & $70.0-74.9$ \\
Mesocephalic & $75.0-79.9$ \\
Brachycephalic & $80.0-84.9$ \\
Hyperbrachycephalic & $85.0-89.9$ \\
Ultrabrachycephalic & $90.0-x$ \\
\hline Cranial index & Maximum skull width x 100 \\
\cline { 2 - 2 } & Maximum skull length \\
\hline
\end{tabular}

Table 2 - Face classification according to the facial index.

\begin{aligned} & \hline Hypereuryprosopic x-79.9 \\ & Euryprosopic $80.0-84.9 \\ &$ Mesoprosopic $85.0-89.9 \\ &$ Leptoprosopic $90.0-94.9 \\ &$ Hyperleptoprosopic $95.0-x \\ &$\hline Facial index Morphological facial height (N-Gn) x 100 \\ & \cline { 2 - 2 } Bizygomatic width (Zyr - Zyl) \\ & \hline\end{aligned}




\section{FACIAL MORPHOLOGY IN PHYSICAL ANTHROPOLOGY}

The description of the human body has been a major concern since ancient times. In ancient Greece, canons based on ratio rules were used to describe the ideal human figure. These canons were once again employed by Renaissance artists such as Leonardo da Vinci and Albrecht Dürer. ${ }^{17,18}$ Many of these neoclassical principles are used today in the arts and medicine..$^{17,18,19}$ The physical anthropology, or anthropometry, provide a scientific foundation to these concepts with a view to evaluating the dimensions and proportions of the human body. ${ }^{17}$

It was only when anthropometric methods were adopted in clinical practice to quantify changes in the craniofacial structure that a wide diversity of human phenotypes and specific features that differentiate individuals and ethnic groups emerged. ${ }^{16,20}$ In different areas of clinical care, standardized anthropometric data have become indispensable for an accurate assessment of the degree of deviation from normality. ${ }^{15,16}$ Examples can be found in plastic surgery, during the treatment of congenital or post-traumatic deformities ${ }^{16,17,21}$, or in legal or forensic medicine when identifying individuals, ${ }^{22}$ or in medical genetics for the diagnosis of dysmorphisms or craniofacial abnormalities. ${ }^{15}$

Attempts to build a comprehensive database covering different populations have been made by the international scientific community. One could cite an international group of scientists led by Leslie Farkas, ${ }^{16}$ who compiled measurements of the face of 1,470 healthy subjects aged between 18 and 30 years, covering the European, Asian and African continents as well as the Middle East. Farkas himself, a plastic surgeon living in Canada, ${ }^{23}$ has devoted much of his career to gleaning
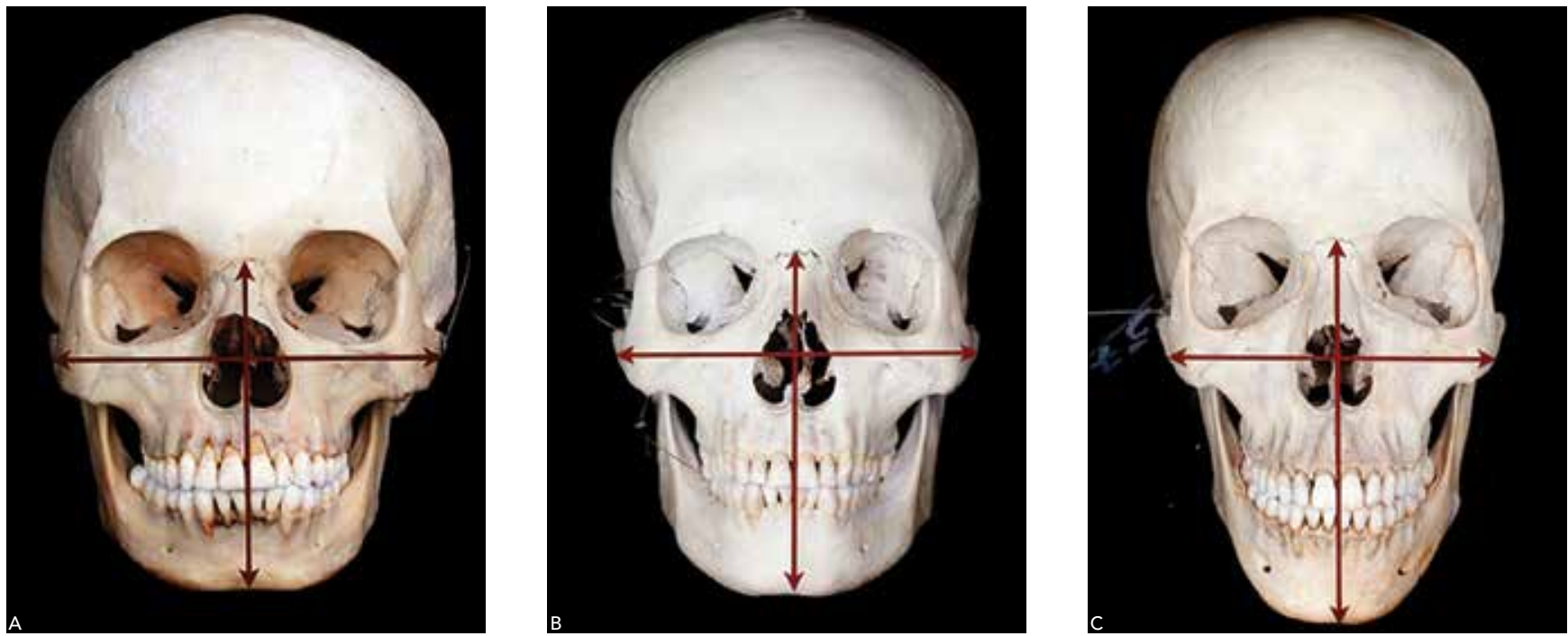

Figure 2 - Facial index: Calculated as the ratio between the morphological face height (N-Gn) and bizygomatic width (Zyr-Zyl). In A, euryprosopic face; in B mesoprosopic face, and in C, leptoprosopic face.
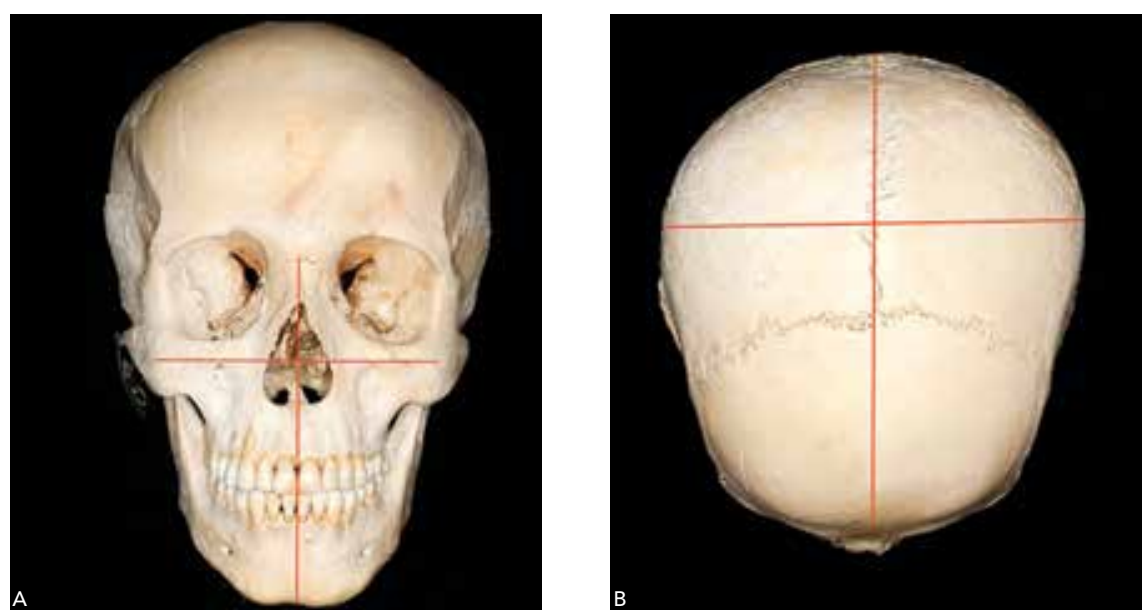

Figure 3 - Skull classified as hyperleptoprosopic (facial index $=96.2 \%)$ in relation to its predominantly vertical facial morphology (A), and hyperbrachycephalic (cranial index $=87.3 \%$ ) in terms of shape $(\mathbf{B})$ 
facial anthropometric data to set the standards for U.S. Caucasian individuals. ${ }^{16,23}$ It should be emphasized that today the advent of globalization and the emergence of multicultural societies have strengthened the importance of differentiating ethnic characteristics in the selection of samples in scientific studies. ${ }^{17}$ Yet another noteworthy concern, especially in medical genetics, regards the standardization of the terminology used to describe craniofacial dysmorphisms or anomalies. In this sense, the objectives are to standardize the terminology and establish consensus regarding definitions and deviations from a standard of normality. ${ }^{15}$

In the medical field, most studies make use of a nomenclature to describe facial patterns in accordance with anthropometry. ${ }^{15,17}$ The term brachycephaly, for example, describes individuals with a cephalic index greater than $81 \%$ and the skull shortened in its anteroposterior dimension. Dolichocephaly, on the other hand, consists of anomalies with a cephalic index below $71 \%$ and an elongated cranial vault. ${ }^{15}$

\section{FACIAL MORPHOLOGY IN ORTHODONTICS}

In orthodontics, the assessment of facial morphology differs from other medical areas, especially by taking as reference the facial profile or side view, rather than the front view of the face. Therefore, the face width is not considered in most classification systems. ${ }^{14}$ This trend can be understood in light of the importance of radiographic cephalometry in modern orthodontics, with the prevalence of analyses based on lateral cephalometric radiographies. ${ }^{7}$ Some of the terminology used to describe the facial pattern are: Dolichofacial, mesofacial or brachyfacial; ${ }^{24}$ hyperdivergent, neutral or hypodivergent; ${ }^{6}$ long, medium or short; ${ }^{7}$ and skeletal open bite or skeletal deep bite. ${ }^{20}$ It should be noted that the terms brachyfacial, dolichofacial and mesofacial, which are commonly used by orthodontists, were introduced in the orthodontic literature in an article by Ricketts in 1960. ${ }^{14,24}$ Some orthodontics textbooks describe the face by resorting to terms such as brachycephalic, dolichocephalic and mesocephalic, and associate specific types of facial morphology with specific dental arch forms. This association should be avoided, since a direct relationship between the shape of the face, skull shape and arch form does not occur in all individuals (Fig 3). ${ }^{25,26}$ The terms euryprosopic, mesoprosopic and leptoprosopic appear in European orthodontic literature and are consistent with other areas that also address facial morphology, such as anthropology, plastic surgery and genetics. ${ }^{14}$ An important issue to consider is that in studies evaluating craniofacial dysmorphisms the terms brachycephaly and dolichocephaly are used to describe deformations of the cranial vault. ${ }^{15}$

\section{THE EFFECTS OF GROWTH}

Any reflection on the meaning and validity of the different systems of facial morphology classification must take into account changes that occur in facial growth. ${ }^{14}$ One particularly significant factor regards evaluating the influence exerted by the head shape on the shape of the face, since the base of the skull is considered a primarily stable structure, from which the face develops in an inferior and anterior direction. ${ }^{8}$

Some studies conducted by Enlow et al, ${ }^{8,27,28}$ are based on the premise that face morphology can be determined by the cranial base, which acts as a mold or "template." According to these studies, individuals with a dolichocephalic head shape have a brain that is long in the anteroposterior direction and narrow in the transverse direction, which results in a longer, flatter skull base, i.e., the angle formed by the floor of the skull is wider. As a result, the entire nasomaxillary complex assumes a lower, more protrusive position, inducing an inferior and posterior rotation of the mandible. Thus, a dolichocephalic head would favor the development of a predominantly long morphology of the face, with a tendency toward a retrognathic mandible and a Class II molar relationship compatible with a leptoprosopic facial type. The same reasoning may be applied to patients with a brachycephalic head shape. Their brains would be wider and more rounded, with a shorter, more angular cranial base, causing a relative retrusion of the nasomaxillary complex and anterior rotation of the mandible. Therefore, these individuals would exhibit features that are closer to a euryprosopic facial pattern. ${ }^{8}$

The influence of cranial morphology on facial type is still not fully understood and few studies directly assess the impact of these variables. Bhat and Enlow ${ }^{27}$ investigated the relationship between facial types and head shape in individuals with Class I and Class II malocclusions that had not been treated orthodontically. They noted that the leptoprosopic facial type and a tendency toward developing a Class II are characteristic of mesocephalic and dolichocephalic skulls; whereas the tendency to develop a protruded mandible is related to brachycephalic skulls. Results from 
other investigations ${ }^{28,29}$ also give grounds to infer a positive relationship between skull morphology and face morphology. However, there is no consensus concerning this association, given that studies ${ }^{25,26}$ using different methodologies have failed to reach the same conclusions. In a study to investigate the craniofacial morphology of bruxist and non-bruxist individuals, Menapace et $\mathrm{a}^{26}$ found no relationship between head shape and craniofacial morphology. In this sample, a frequent association was found between dolichocephalic head shape and euryprosopic facial type.

\section{FINAL CONSIDERATIONS}

The growing presence of orthodontics in the context of scientific research makes it necessary to adopt a language consistent with other biological fields.

Terminology standardization is essential to facilitate communication among professionals, enabling comparisons to be made between different studies and affording increasingly evidence-based outcomes.

Nevertheless, it is a fact that currently a non-homogeneous nomenclature is still employed in ortho- dontics to describe facial patterns, a terminology that often differs from that used in other medical fields. This is due in large measure to a strong influence exerted by cephalometrics as a method to study craniofacial growth, notably based on studies that emphasize the role of skull morphology in determining the shape of the face. Investigating the influence of skull shape on face shape can provide a benchmark to validate the nomenclature used in orthodontics. If the assertion that skull type determines face type is true then it would not be wrong to use terms derived from the cephalic index, such as "brachyfacial", "mesofacial" and "dolichofacial," to describe the face. On the other hand, in the event that it is not possible to determine this correlation, the use of this nomenclature, as well as hindering communication with other medical specialties, would not be justified - and the terms "euryprosopic", "mesoprosopic" and "leptoprosopic" should be incorporated into orthodontic terminology. These issues point to the need for further research on this topic.
1. Grauer D, Cevidanes LSH, Styner MA, Ackerman JL, Proffit WR. Pharyngeal airway volume and shape from cone-beam computed tomography: relationship to facial morphology. Am J Orthod Dentofacial Orthop. 2009:136(6):805-14.

2. Pepicelli A, Woods $M$, Briggs $C$. The mandibular muscles and their importance in orthodontics: a contemporary review. Am J Orthod Dentofacial Orthop. 2005;128(6):774-80.

3. Chan HJ, Woods M, Stella D. Mandibular muscle morphology in children with different vertical facial patterns: a 3-dimensional computed tomography study. Am J Orthod Dentofacial Orthop. 2008:133(1):10e1-13.

4. Tsunori M, Mashita M, Kasai K. Relationship between facial types and tooth and bone characteristics of the mandible obtained by $\mathrm{CT}$ scanning. Angle Orthod. 1998:68(6):557-62.

5. Dibbets JM. Morphological associations between the Angle classes. Eur J Orthod. 1996:18(2):111-8

6. Siriwat PP, Jarabak JR. Malocclusion and facial morphology Is there a relationship? Angle Orthod. 1985;55(2):127-38.

7. Bishara SE, Jakobsen JR. Longitudinal changes in three normal facial types. Am J Orthod. 1985;88(6):466-502.

8. Enlow DH. Facial growth. 3rd ed. Philadelphia: WB Saunders; 1990

9. Horn AJ, Thiers-Jegou I. Class II deep bite faces: one-phase or two-phase treatment? World J Orthod. 2005;6(2):171-9.

10. Edler R, Agarwal P, Wertheim D, Greenhill D. The use of anthropometric proportion indices in the measurement of facial attractiveness. Eur J Orthod. 2006:28(3):274-81

11. Farkas, LG, Munro IR. Anthropometric facial proportions in Medicine. Springfield: Charles C. Thomas Publisher; 1986.

12. Sicher H. Oral anatomy. 6th ed. St Louis: Mosby; 1975.

13. Rakosi T, Jonas I, Graber T. Orthodontic diagnosis (Color Atlas of Dental Medicine). 1st ed. Thieme; 1993.

14. Collett AR, West VC. Terminology of facial morphology in the vertical dimension. Aust Dent J. 1993;38(6):480-1.

15. Allanson JE, Cunniff C, Hoyme HE, McGaughran J, Muenke M, Neri G. Elements of morphology: standard terminology for the head and face. Am J Med Genet. 2009:149A(1):6-28
16. Farkas LG, Katic MJ, Forrest CR, Alt KW, Bagic I, Baltadjiev G, et al. International anthropometric study of facial morphology in various ethnic groups/races. J Craniofac Surg. 2005;16(4):615-46.

17. Arslan SG, Genç C, Odabaş B, Kama JD. Comparison of facial proportions and anthropometric norms among Turkish young adults with different face types. Aesthetic Plast Surg. 2008 Mar;32(2):234-42.

18. Kolar JC, Salter EM. Craniofacial anthropometry: practical measurement of the head and face for clinical, surgical, and research use. Springfield: C.C. Thomas; 1997.

19. Edler R. The use of anthropometric proportion indices in the measurement of facial attractiveness. Eur J Orthod. 2005:28(3):274-81.

20. Sassouni V. A classification of skeletal facial types. Am J Orthod. 1969;55(2):109-23

21. Ward RE, Jamison PL, Farkas LG. Craniofacial variability index: a simple measure of normal and abnormal variation in the head and face. Am J Med Genet. 1998:80(3):232-40.

22. Mane DR, Kale AD, Bhai MB, Hallikerimath S. Anthropometric and anthroposcopic analysis of different shapes of faces in group of Indian population: a pilot study. J Forensic Leg Med. 2010;17(8):421-5.

23. Naini FB. Leslie G. Farkas, 1915-2008. Am J Orthod Dentofacial Orthop. 2009;136(4):614.

24. Ricketts R. A foundation for cephalometric communication. Am J Orthod. 1960:46(1):230-57.

25. Kerr WJ, Hirst D. Craniofacial characteristics of subjects with normal and postnormal occlusions - a longitudinal study. Am J Orthod Dentofacial Orthop. 1987:92(3):207-12.

26. Menapace SE, Rinchuse DJ, Zullo T, Pierce CJ, Shnorhokian H. The dentofacial morphology of bruxers versus non-bruxers. Angle Orthod. 1994;64(1):43-52.

27. Bhat M, Enlow DH. Facial variations related to headform type. Angle Orthod. 1985:55(4):269-80.

28. Enlow DH, McNamara JA. The neurocranial basis for facial form and pattern. Angle Orthod. 1973:43(3):256-70.

29. Enlow DH, Kuroda T, Lewis AB. The morphological and morphogenetic basis for craniofacial form and pattern. Angle Orthod. 1971;41(3):161-88. 